\title{
The effect of ethanolic leaves extract of Hymenodictyon floribundun on inflammatory biomarkers: a data-driven approach
}

\author{
Abdullahi Garba Usman ${ }^{1 *}$,, Mubarak Hussaini Ahmad², Rabi'u Nuhu Danraka² and Sani Isah Abba ${ }^{3}$
}

\begin{abstract}
Background: Medicinal plants are used to manage pain and inflammatory disorders in traditional medicine. A scientific investigation could serve as a basis for the determination of molecular mechanisms of antinociceptive and antiinflammatory actions of herbal products. In this work, we used both artificial intelligence (Al) based models inform of adaptive neuro-fuzzy inference system and artificial neural network (ANN) as well as a linear model, namely; stepwise linear regression in modelling the performance of four different inflammatory biomarkers namely; interleukin (1L)-1 $\beta$, $1 \mathrm{~L}-6$, tumour necrosis factor (TNF)- $a$ and prostaglandin E2 $\left(\mathrm{PGE}_{2}\right)$. This modelling was done using number of abdominal writes, the reaction time of paw licking in mice and paw oedema diameter as the input variables.

Results: Four different performance indices were employed, which are determination coefficient (DC), root mean squared error (RMSE), mean square error (MSE) and correlation co-efficient (CC). The results have shown the superiority of the Al-based models over the linear model.
\end{abstract}

Conclusions: The overall quantitative and visualized comparison of the results showed that adaptive neuro-fuzzy inference system outperformed the ANN and SWLR models in modelling the performance of the four inflammation biomarkers in both the calibration and verification phases.

Keywords: Medicinal plants, Antiinflammatory, Inflammatory biomarkers, Artificial intelligence, Stepwise linear regression

\section{Background}

Pain is a disturbing sensation associated with emotional experience due to actual or possible tissue injury and usually manifest as a typical symptom in the diagnosis of various disorders (Abdulmalik et al. 2011). Inflammation could serve as a body's response to tissue damage, cellular death, tumour, ischemic and degenerative diseases (Azab et al. 2016). It helps the body to eliminate injurious agents by serving as immunity (Rafieian-kopaei et al. 2017). Several endogenous substances including tumour necrosis factor $\alpha$ (TNF- $\alpha)$, interleukins (IL), and

\footnotetext{
*Correspondence: abdullahigusman@gmail.com

1 Department of Analytical Chemistry, Faculty of Pharmacy, Near East

University, Nicosia 99138, Turkish Republic of Northern Cyprus

Full list of author information is available at the end of the article
}

prostaglandins play a role in the pathogenesis of of pain and inflammation (Azab et al. 2016).

Non-steroidal anti-inflammatory drugs (NSAIDs) as the most common drugs used to manage pain and inflammation elicit analgesic and antiiinflammatory action by inhibiting cyclooxygenase (COX) enzyme, which interferes with PG synthesis (Adedayo et al. 2019). The opioids have also been employed to manage severe pain. However, they are asscociated with some serious side effects including gastrointestinal irritation, bleeding, gastric ulceration, tolerance, dependence, respiratory depression, drowsiness, nausea and vomiting (Abdulmalik et al. 2011; Ezeja et al. 2011). Besides, the NSAIDS are also associated with liver diseases, risk of myocardial infarction (Kearney et al. 2006), erectile dysfunction (Shiri et al. 2006) and renal toxicity (Schneider et al. 2006). Steroids are commonly used to treat 
inflammation (Rafieian-kopaei et al. 2017). However, they are also associated with adverse effects such as cardiovascular effects (fluid retention, hypertension), hyperglycaemia, insomnia, irritability, psychotic-like symptoms, rashes, gastric and oesophageal ulcerations, weight gain, immunosuppression, increased risk of osteoporosis, impaired wound healing and many more (Kapugi and Cunningham 2019).

The pharmacological investigations of medicinal plants have encouraged the search for newer and more efficacious therapeutic agents (Akindele et al. 2012). Some important analgesic agents, such as acetylsalicylic acid and morphine, were sourced from medicinal plants (Abubakar et al. 2020). Therefore, there is increasing interest in developing effective anti-inflammatory and analgesic drugs from herbal preparations in managing pain and inflammation (Adedayo et al. 2019).

The use of different pharmacological and machine learning methods is essential to investigate the molecular pathogenesis of human diseases and serve as a basis for developing novel therapeutic agents (Xu et al. 2020). For instance, Zihad et al. (2018) used a computational approach to identify bioactive compounds with activity against COXs as a basis for treating pain and inflammation. Also, ChagasPaula et al. (2015) predicted the anti-inflammatory activity of natural compounds from Asteraceae species using an artificial neural network (ANN) model. Furthermore, Pandya et al. (2020), in their study, reported the use of computational approaches to predict the antiinflammatory action of bioactive compounds from Murraya koenigii and their pharmacological effects on COX-1 and COX-2.

The Hymenodictyon floribundum (Rubiaceae) is a small tree that is widely available in tropical Africa. The trunk bark of the plant has been utilized to treat fever in African countries (Borges et al. 2010). Previous research has shown that the trunk of the plant contains scopolin,scopoletin, 3 -O- $\beta$ D-glucopyranosyl- $\beta$-sitosterol and hymeselsin (Borges et al. 2010).

The leaves of Hymenodictyon floribundum is claimed to have antinociceptive and anti-inflammatory potentials by the ethnic people of Zaria, Kaduna State, Nigeria. However, no documented scientific investigation was conducted to ascertain its its effect on inflammatory biomarkers. Therefore, this article aims to investigate the effect of ethanolic leaves extract of Hymenodictyon floribundun on inflammatory biomarkers using data driven-approach.

\section{Methods}

\section{Collection and identification of Hymenodictyon floribundum}

The Hymenodictyon floribundum was collected from Kargil Hill along Birnin Gwari road, Zaria Local Government of Kaduna State, Nigeria, in October 2019. The identification of the plant was done by a taxonomist, Mallam Namadi Sambo, at the Herbarium unit of the Department of Botany, Ahmadu Bello University, Zaria, Kaduna State, Nigeria. The plant was compared with an existing specimen already deposited in the herbarium. The plant's voucher number (ABU900124) was obtained.

\section{Experimental animals}

We obtained adult Wistar rats $(150-200 \mathrm{~g})$ and Swiss albino mice (18-25 g) from the Department of Pharmacology and Therapeutics, Ahmadu Bello University, Zaria, Nigeria. The experimental animals were housed in an adequately-ventilated cages, and provided with rodent diet (Vital feed, Jos, Nigeria) with water provision ad libitum. They were maintained under appropriated laboratory conditions (room temperature $22 \pm 3{ }^{\circ} \mathrm{C}$, relative humidity $30-70 \%$ with 12 -h light and 12 -h dark). The animals were kept in polypropylene cages for two weeks and allowed to acclimatise to the laboratory environment prior to the commencement of the experiment. The permission to conduct the experimental procedures were granted by the Ahmadu Bello University Ethical Committee on Animal Use and Care (approval number: ABUCAUC/2020/011) and carried out based on the guidelines of ARRIVE (Animal Research: Reporting of In Vivo Experiments). After completing the experimental procedures, all the animals were anaesthetized with chloroform and quickly euthanized by cervical dislocation. They were immediately buried deeply according to the institutional guideline for proper disposal of laboratory animals remain.

\section{Drugs and chemicals}

The drugs and chemicals used in this studies are ethanol, carrageenan, chloroform (Sigma Aldrich, St. Louis Mo, USA), morphine sulphate (Martindale Pharmaceuticals, UK), piroxicam (RotexMedica, Germany), glacial acetic acid (May and Baker limited, Dagenham, England), normal saline and distilled water.

\section{Extraction procedure}

The leaves of Hymenodictyon floribundun were allowed to dry under shade and size-reduced into a fine powdered form with the aid of mortat and pestle. $700 \mathrm{~g}$ of the powdered leaves were extracted exhaustively with ethanol using the soxhlet apparatus for 72-h. The solvent was removed by placing the extract on a water bath set at $45^{\circ} \mathrm{C}$.

Finally, the extract was weighed and kept in a wellclosed and labelled container. It was then called as "ethanolic leaves extract of Hymenodictyon floribundun" (EEHF). 


\section{Acute toxicity determination}

We investigated the acute toxicity study of EEHF in rats and mice based on the guideline specified by the Organization of Economic Co-operation and Development (OECD) 423 (OECD 2001). The oral median lethal dose $\left(\mathrm{LD}_{50}\right)$ was investigated following administration of th extract to nulliparous and non-pregnant female rats and mice. Two groups containing three animals were fasted before dosing (food was withheld overnight for rats and $3 \mathrm{~h}$ for mice with adequate access to water). In the initial phase, a dose of $2000 \mathrm{mg} / \mathrm{kg}$ of the extract was administered to each animal and observed for 48-h for any sign and symptom of toxicity, including death. The same procedure was done in the second phase but at $5000 \mathrm{mg} / \mathrm{kg}$ and the animals were observed for signs and symptoms of toxic effects of the extract, including tremor, convulsion, salivation, lacrimation, diarrhoea, lethargy, sleep, respiratory, behavioural pattern, time of onset of toxicity if any, and length of the recovery period as well as the time of death one time after every 30 min within the first 4-h and then subsequently for 14-days consecutively.

\section{Acetic acid-induced writhing test}

We adopted the procedure previously used by Okpo et al. (2001). Thirty mice were divided randomly into 5 groups containg six animals in each group $(n=6)$. Group I received distilled water $(10 \mathrm{ml} / \mathrm{kg})$, groups II, III, IV received graded doses of EEHF $(250,500$, and $1000 \mathrm{mg} /$ $\mathrm{kg}$ ), respectively and the group $\mathrm{V}$ received morphine $(10 \mathrm{mg} / \mathrm{kg})$. One hour after the treatment, $0.6 \% \mathrm{v} / \mathrm{v}$ of acetic acid $(10 \mathrm{ml} / \mathrm{kg})$ was orally administered to each mouse. Subsequently, after 5 min of acetic acid injection, the number of abdominal constriction observed in each mouse was counted for $10 \mathrm{~min}$.

\section{Hot plate test}

The method previously described by Okolo et al. (1995) was used. 30 mice wererandomly divided into 5 groups containing six mice $(n=6)$. Group I received distilled water $(10 \mathrm{ml} / \mathrm{kg})$. Group II, III and IV were administered the graded doses of EEHF (250, 500 and $1000 \mathrm{mg} / \mathrm{kg}$ ), respectively, while group $\mathrm{V}$ received morphine $(10 \mathrm{mg} /$ $\mathrm{kg})$. The animals were placed individually on a hot plate set at a temperature of $\left(45 \pm 1{ }^{\circ} \mathrm{C}\right)$ for $15 \mathrm{~s}$. The pain latecy was observed and recorded at 0, 60, 90, 120 and $150 \mathrm{~min}$ when the animals licked their paws or jumped from the hot plate.

\section{Carrageenan-induced paw oedema}

The method previously described by Winter et al. (1962) was used. 30 male rats were randomly grouped into 5 different groups $(n=6)$. Group I received distilled water $(10 \mathrm{ml} / \mathrm{kg})$, while group $\mathrm{V}$ received piroxicam $(10 \mathrm{mg} /$ $\mathrm{kg})$. Group II, III and IV received EEHF (250, 500 and $1000 \mathrm{mg} / \mathrm{kg}$ ), respectively. $30 \mathrm{~min}$ after the treatment, $1 \%$ of freshly prepared suspension of carrageenan $(0.1 \mathrm{ml})$ was injected into the sub-plantar surface of rat right hind paw. The diameter of the oedematous paw was measured

Table 1 Correlation analysis performance of the variables

\begin{tabular}{|c|c|c|c|c|c|c|c|c|c|c|c|c|c|c|c|c|}
\hline \multirow[t]{2}{*}{ Variables } & \multirow[t]{2}{*}{ ABD } & \multicolumn{5}{|c|}{ NPL (Min.) } & \multicolumn{6}{|c|}{ POD (Min.) } & \multicolumn{4}{|l|}{ IB } \\
\hline & & 0 & 60 & 120 & 180 & 240 & 0 & 60 & 120 & 180 & 240 & 300 & IL-1B & IL-6 & TNF-a & PGE2 \\
\hline $\mathrm{ABD}$ & 1 & & & & & & & & & & & & & & & \\
\hline 0 & 0.1 & 1.0 & & & & & & & & & & & & & & \\
\hline 60 & -0.6 & 0.2 & 1.0 & & & & & & & & & & & & & \\
\hline 120 & -0.7 & 0.1 & 0.8 & 1.0 & & & & & & & & & & & & \\
\hline 180 & -0.7 & 0.1 & 0.7 & 0.6 & 1.0 & & & & & & & & & & & \\
\hline 240 & -0.4 & 0.1 & 0.2 & 0.1 & 0.2 & 1.0 & & & & & & & & & & \\
\hline 0 & -0.3 & 0.3 & 0.0 & 0.1 & 0.2 & 0.2 & 1.0 & & & & & & & & & \\
\hline 60 & 0.3 & 0.0 & 0.2 & 0.2 & 0.4 & 0.0 & 0.1 & 1.0 & & & & & & & & \\
\hline 120 & 0.7 & 0.1 & 0.6 & 0.6 & 0.7 & 0.1 & 0.1 & 0.4 & 1.0 & & & & & & & \\
\hline 180 & 0.7 & 0.3 & 0.4 & 0.4 & 0.4 & 0.2 & 0.1 & 0.4 & 0.6 & 1.0 & & & & & & \\
\hline 240 & 0.8 & 0.2 & 0.6 & 0.6 & 0.6 & 0.2 & 0.2 & 0.3 & 0.8 & 0.8 & 1.0 & & & & & \\
\hline 300 & 0.8 & 0.1 & 0.5 & 0.5 & 0.5 & 0.3 & 0.1 & 0.2 & 0.7 & 0.7 & 0.9 & 1.0 & & & & \\
\hline IL-1B & 0.1 & 0.1 & 0.1 & 0.1 & 0.3 & 0.1 & 0.4 & 0.3 & 0.2 & 0.2 & 0.2 & 0.0 & 1.0 & & & \\
\hline IL-6 & -0.1 & 0.2 & 0.1 & 0.0 & 0.3 & 0.2 & 0.3 & 0.1 & 0.3 & 0.2 & 0.1 & 0.2 & 0.4 & 1.0 & & \\
\hline TNF-a & 0.3 & 0.0 & 0.3 & 0.2 & 0.3 & 0.2 & 0.1 & 0.0 & 0.3 & 0.4 & 0.4 & 0.3 & 0.6 & 0.3 & 1.0 & \\
\hline PGE2 & 0.6 & 0.1 & 0.4 & 0.5 & 0.4 & 0.2 & 0.2 & 0.7 & 0.5 & 0.5 & 0.5 & 0.5 & 0.2 & 0.1 & 0.1 & 1 \\
\hline
\end{tabular}


using a vernier caliper and recorded at $0,1,2,3,4$ and $5 \mathrm{~h}$.

\section{Investigation of the inflammatory biomarkers in the antiinflammatory properties of Hymenodictyon floribundun}

In another separate experiment, the carrageenan-induced paw oedema previously described above was adopted. This time, the hind paw oedema was measured and recorded at different time intervals $(0,1,2$, and $3 \mathrm{~h})$ with the aid of the vernier caliper. The rats were immidiately anaesthetised using chloroform, euthanized by cervical disloaction, and the blood was collected from the orbital sinus into the ethylenediamine tetraacetic acid (EDTA) containing bottle. The blood collected was centrifuged at 3000 revolutions per minute $(\mathrm{rpm})$ for $15 \mathrm{~min}$ which was used to estimate the levels of pro-inflammatory biomarkers (PGE2, IL-1 $\beta$, IL-6, and TNF- $\alpha$ ) according to the manufacturer's instructions.

\section{Adaptive-neuro-fuzzy inference system (ANFIS)}

ANFIS serves as a general estimator, which responds to various complications. It was originated from feed-forward networks and adaptive multi-layer. It constitutes input variables together with the fuzzy rule that consist of input-output variables along with fuzzy rule based on the Takagi-Sugeno type. The main components of the fuzzy database are fuzzier and defuzzifier. The fuzzy logic converts the input parameters into fuzzy values by the use of membership functions.

Nodes play a role as a membership function (MFs), which allowed the modelling of the association between the input and output parameters. Its membership function includes trapezoidal triangular, sigmoid, and Gaussian (Elkiran et al. 2019).

Based on the assumption Eqs. 1 and 2 are derived.

Rule 1 : if $\mu(x)$ is $A_{1}$ and $\mu(y) B_{1}$ then $f_{1}=p_{1} x+q_{1} y+r_{1}$

Rule 2 : if $\mu(x)$ is $A_{2}$ and $\mu(y) B_{2}$ then $f_{2}=p_{2} x+q_{2} y+r_{2}$
$A_{1}, B_{1}, A_{2}, B_{2}$. parameters are membership functions for $x$ and $y$, and inputs $p_{1}, q_{1}, r_{1}, p_{2}, q_{2}, r_{2}$, are output function data. The structure of ANFIS and its formulation is in line with a neural network configuration of five layers. Refer to (Khademi et al. 2016) for more information about ANFIS.

\section{Multi-layer perceptron (MLP) neural network}

Multi-layer perception (MLP) neural network is among the typical examples of ANN that could manage a nonlinear system. Therefore, researchers recognize it as a universal approximator compare to other formsof ANN (Choubin et al. 2016).The structural features of MLP include an input layer, a hidden layer and an output layer, in a similar manner to other distinguished ANNs (Kim and Singh 2014; Pham et al. 2019). On a general note, the nodes of the independent layers are connected to the hidden and output layers. The transduction of the signal are then transferred from the input layer into e output layer with the help of biases and weights through mathematical procedures. The MLP comprises of an input together with one or more hidden layers and output layers in its structural framework much similar to ANN (Committee 2000; Kim and Lee 2017).

$$
y_{i}=\sum_{j=1}^{N} w_{j i} x_{j}+w_{i 0}
$$

$N$ denotes the total number of nodes within the node's top layer, $\mathrm{i} ; w_{j i}$ is the weight between the nodes, $i$ and $j$ in the upper layer; $x_{j}$ defines the output that is derived from node $j ; w_{i 0}$ is the bias in the node $i$, and $y_{i}$ defines the input signal of node $i$ which crosses via the transfer function.

\section{Step-wise-linear regression (SWLR)}

Generally, linear regression (LR) is among the main computational approaches in modeling a lot of input and output variables. It is necessary to note that there has been a correlation between single and multiple variables in finding the optimal set of the parameters that

Table 2 Performance of 1L-1B inflammatory biomarker

\begin{tabular}{|c|c|c|c|c|c|c|c|c|}
\hline \multirow[t]{2}{*}{ Models } & \multicolumn{4}{|c|}{ Calibration } & \multicolumn{4}{|c|}{ Verification } \\
\hline & $\mathrm{DC}$ & $\mathrm{CC}$ & RMSE & MSE & $\mathrm{DC}$ & CC & RMSE & MSE \\
\hline MLP-1L-1B & 0.9419 & 0.9705 & 18.5051 & 342.439 & 0.92760 & 0.96313 & 9.95155 & 99.0326 \\
\hline ANFIS-1L-1B & 0.9996 & 0.9998 & 1.52768 & 2.33380 & 0.99999 & 0.99996 & 0.10699 & 0.01147 \\
\hline SWLR-1L-1B & 0.8488 & 0.9213 & 29.8442 & 890.676 & 0.8346 & 0.91354 & 30.786 & 947.778 \\
\hline
\end{tabular}

The best performing model are written in bold

$\mathrm{DC}=$ Determination co-effient, $\mathrm{CC}=$ Correlation co-efficient, $\mathrm{RMSE}=$ Root mean square error, $\mathrm{MSE}=$ Mean square error, $n=6$ 

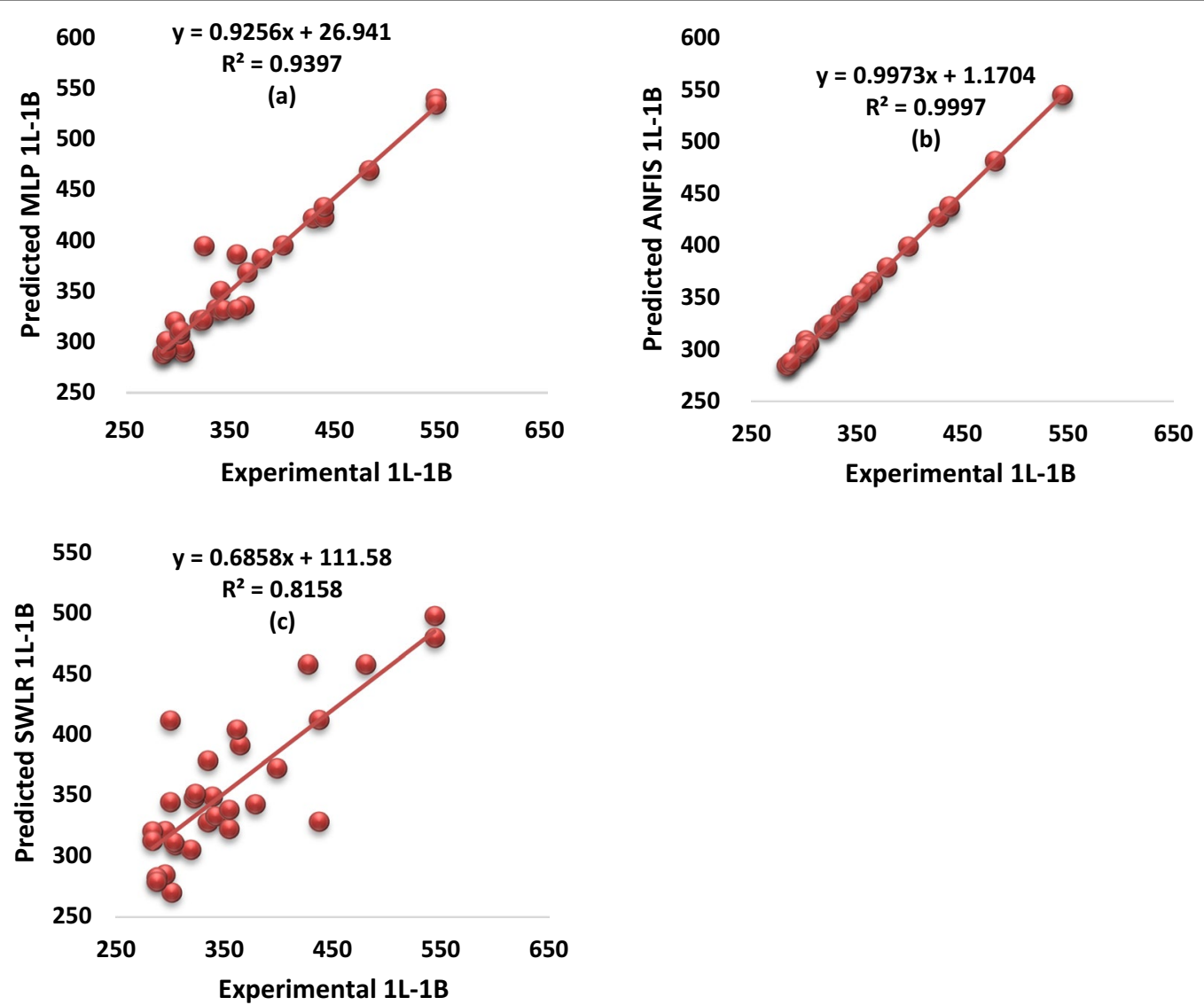

Fig. 1 Scatter plots for a MLP, b ANFIS and c SWLR for 1L-1B

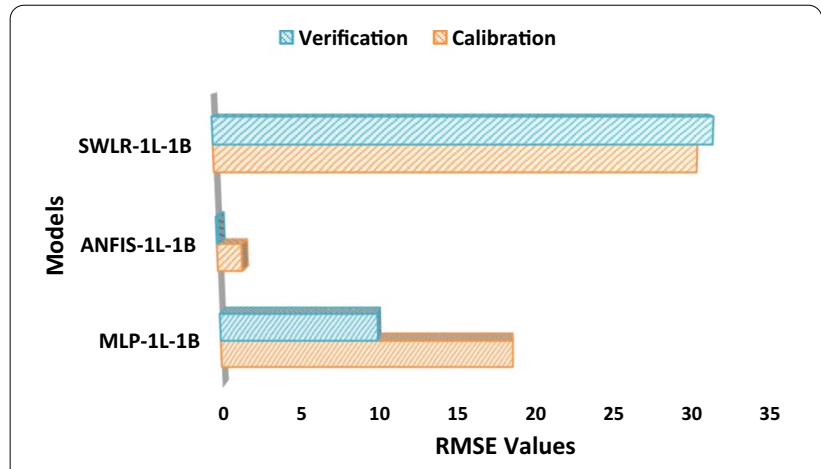

Fig. 2 ComparativeRMSE values of the models in modelling 1L-1B

give the highest prediction efficiency, which is related to the output variable (Abba et al. 2020a, b, c). Various modellers described the systematic regression as an advancement selection that utilizes the optimal set of the input data by deleting or adding the variables through the influence of the residual sum of the squares (Abba et al. 2020a, b, c).
The SWLR abides by the systematic changes of the variables by checking their impacts. Any variable that fails to contribute and satisfy the process of the model would be deleted in a step-wise manner in order to eliminate its impact (Mohammadhassani et al. 2013). MLR could be used to demonstrate the theory of SWLR (Lee et al. 2017).The systematic regression is the procedure of adding or removing an input in constant from LR (Gaya et al. 2020).

\section{Evaluation metrics of the models}

The performance skills are checked with the help of various parameters based on comparison between the expected and calculated value for any type of datadriven approach.

In the present work, we used two statistical errors namely; root mean-squared error (RMSE) and meansquared error (MSE) for determination coefficient (DC) as a goodness-of-fit, correlation coefficient (CC) and evaluation of the two models. 
Table 3 Performance of 1L-6 inflammatory biomarker

\begin{tabular}{|c|c|c|c|c|c|c|c|c|}
\hline \multirow{2}{*}{ Models } & \multicolumn{4}{|c|}{ Calibration } & \multicolumn{4}{|c|}{ Verification } \\
\hline & $\overline{D C}$ & $\mathrm{CC}$ & RMSE & MSE & $\overline{D C}$ & CC & RMSE & MSE \\
\hline MLP-1L-6 & 0.7971 & 0.8928 & 77.6708 & 6032.766 & 0.6450 & 0.8031 & 89.8350 & 8070.327 \\
\hline ANFIS-1L-6 & 0.9999 & 0.9999 & 0.21906 & 0.047991 & 1.0000 & 1.0000 & 0.00000 & 0.0000 \\
\hline SWLR-1L-6 & 0.7382 & 0.8591 & 88.2317 & 7784.8414 & 0.61340 & 0.78319 & 91.23550 & 8323.9164 \\
\hline
\end{tabular}

The best performing model are written in bold

$\mathrm{DC}=$ Determination Co-efficient, $\mathrm{CC}=$ Correlation co-efficient, $\mathrm{RMSE}=$ Root mean sqaure error, $\mathrm{MSE}=$ Mean square error, $n=6$
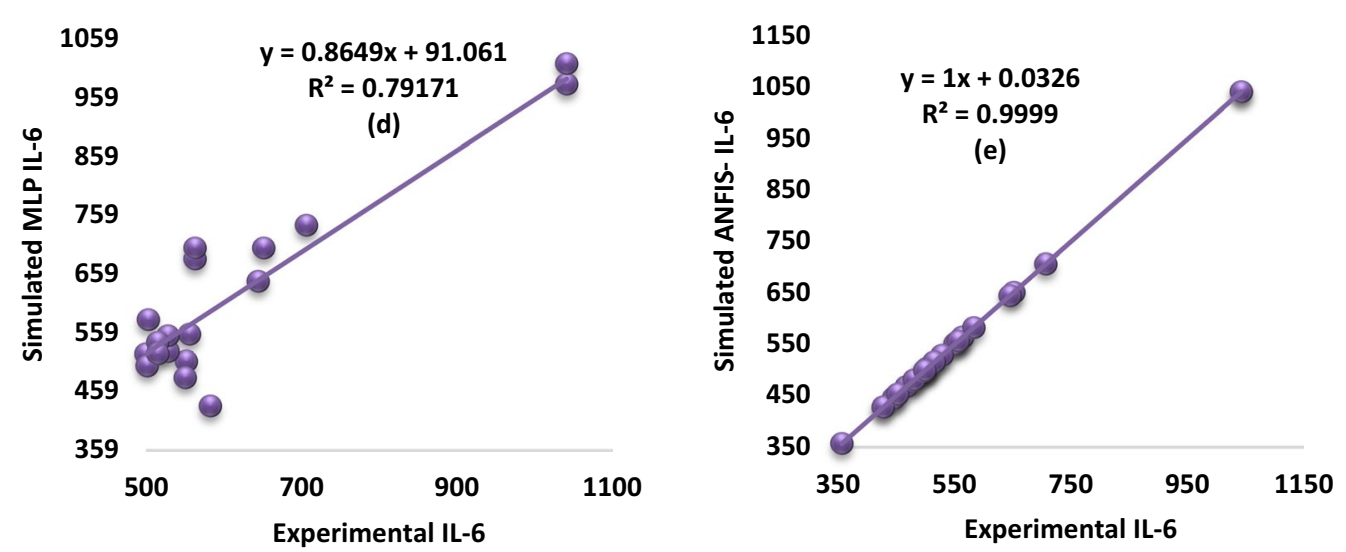

1100

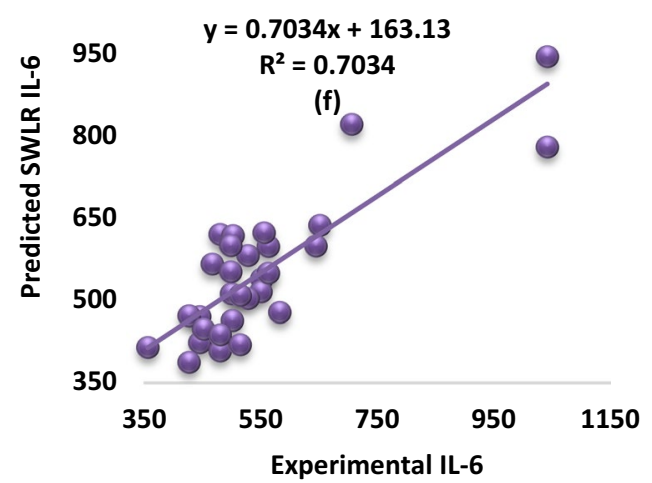

Fig. 3 Scatter plots for $\mathbf{d}$ MLP, e ANFIS and $\mathbf{f}$ SWLR for 1L-6

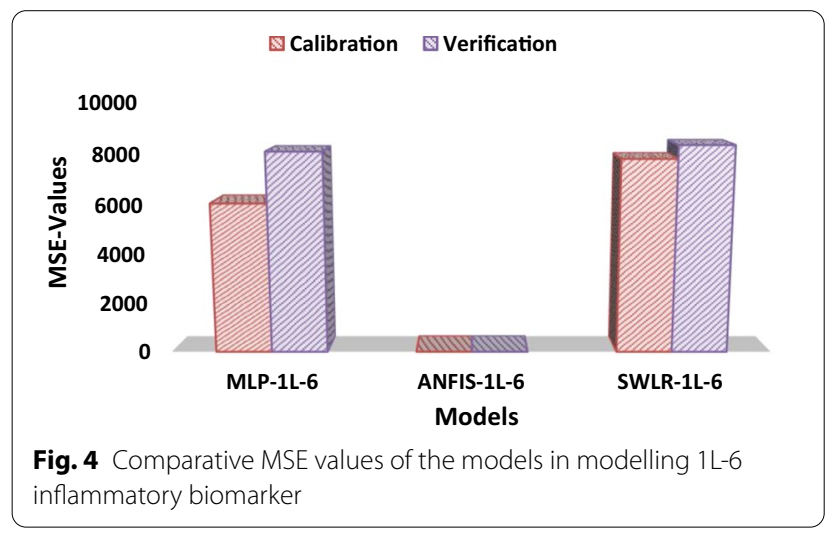

$$
\begin{aligned}
& \mathrm{DC}=1-\frac{\sum_{j=1}^{N}\left[(Y)_{\mathrm{obs}, j}-(Y)_{\mathrm{com}, j}\right]^{2}}{\sum_{j=1}^{N}\left[(Y)_{\mathrm{obs}, j}-\overline{(Y)}_{\mathrm{obs}, j}\right]^{2}} \\
& \mathrm{CC}=\frac{\sum_{i=1}^{N}\left(Y_{\mathrm{obs}}-\bar{Y}_{\mathrm{obs}}\right)\left(Y_{\mathrm{com}}-\bar{Y}_{\mathrm{com}}\right)}{\sqrt{\sum_{i=1}^{N}\left(Y_{\mathrm{obs}}-\bar{Y}_{\mathrm{obs}}\right)^{2}} \sum_{i=1}^{N}\left(Y_{\mathrm{com}}-\bar{Y}_{\mathrm{com}}\right)^{2}} \\
& \mathrm{RMSE}=\sqrt{\frac{\sum_{i=1}^{N}\left(Y_{\mathrm{obs} i}-Y_{\mathrm{com} i}\right)^{2}}{N}}
\end{aligned}
$$


Table 4 Performance of PGE2inflammatory biomarker

\begin{tabular}{|c|c|c|c|c|c|c|c|c|}
\hline \multirow[t]{2}{*}{ Models } & \multicolumn{4}{|c|}{ Calibration } & \multicolumn{4}{|c|}{ Verification } \\
\hline & $\mathrm{DC}$ & $\mathrm{CC}$ & RMSE & MSE & $\mathrm{DC}$ & $\mathrm{CC}$ & RMSE & MSE \\
\hline MLP-PGE2 & 0.65 & 0.80 & 75.96 & 5770.56 & 0.72 & 0.85 & 31.40 & 986.05 \\
\hline ANFIS-PGE2 & 1.00 & 1.00 & 0.00 & 0.00 & 1.00 & 1.00 & 0.22 & 0.05 \\
\hline SWLR-PGE2 & 0.85 & 0.92 & 49.63 & 2463.26 & 0.85 & 0.92 & 23.26 & 540.84 \\
\hline
\end{tabular}

The best performing model are written in bold

$\mathrm{DC}=$ Determination co-efficient, $\mathrm{CC}=$ Correlation co-efficient, $\mathrm{RMSE}=$ Root mean square error, $\mathrm{MSE}=$ Mean squared error, $n=6$
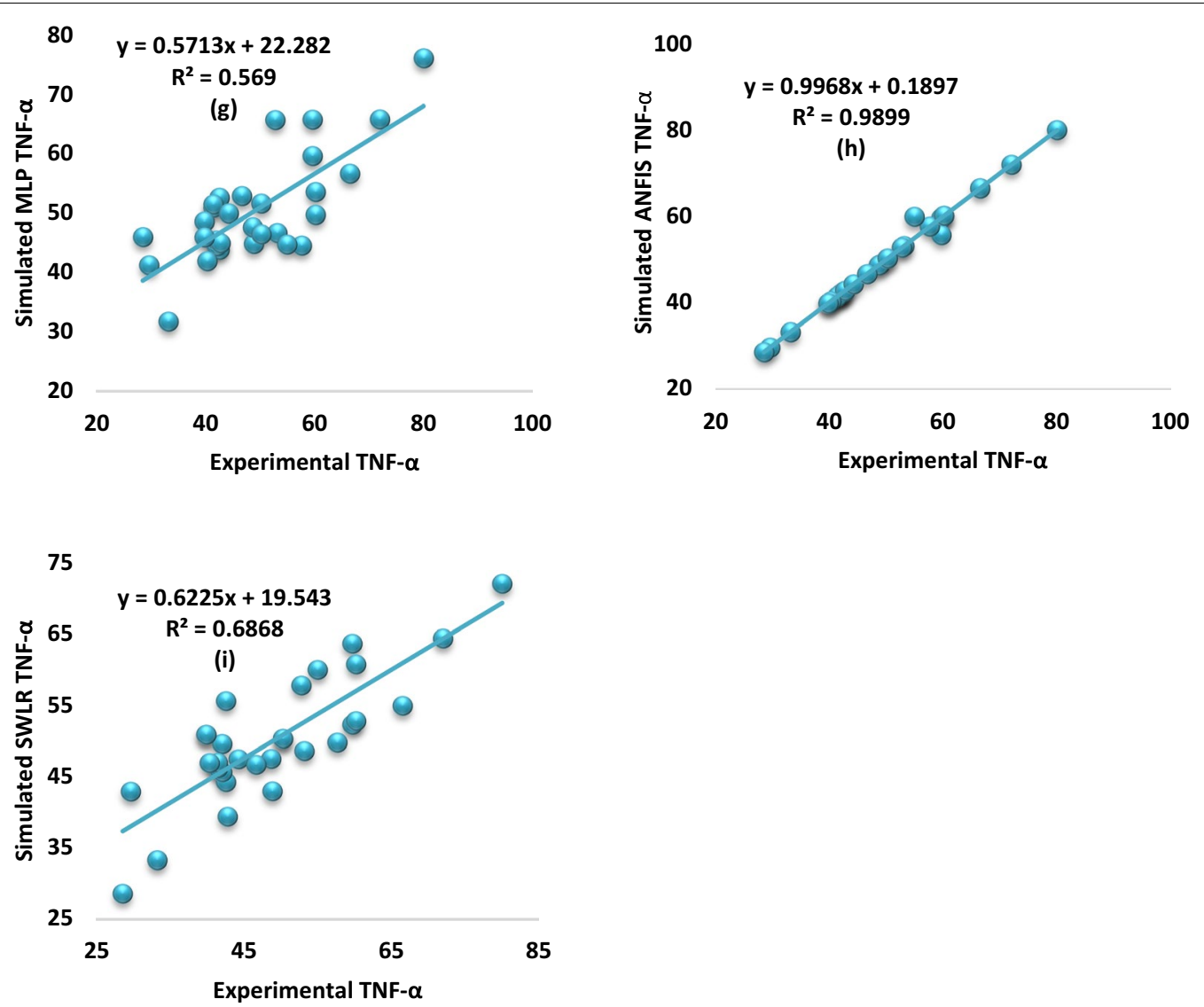

Fig. 5 Scatter plots for $\mathbf{g}$ MLP, $\mathbf{h}$ ANFIS and i SWLR forTNF- $a$

$$
\text { MSE }=\frac{1}{N} \sum_{i=1}^{N}\left(Y_{\mathrm{obs} i}-Y_{\mathrm{com} i}\right)^{2}
$$

where $N, Y_{\mathrm{obs} i}, \bar{Y}$ and $Y_{\mathrm{com} i}$ are data number, data observed, average value of the data observed and computed values, respectively.

\section{Data set description and validation of the models}

For effective data-driven approaches, the main objective is to make the model to provide a set of data from the indicators in use as a basis to reliably predict the unknown variables. Looking at the fact that some limitations examples overfitting, the satisfactory training performance do not consistently comply with the testing performance. Different validation approaches such as $\mathrm{k}$-fold cross-validation, holdout, leaving one out, 


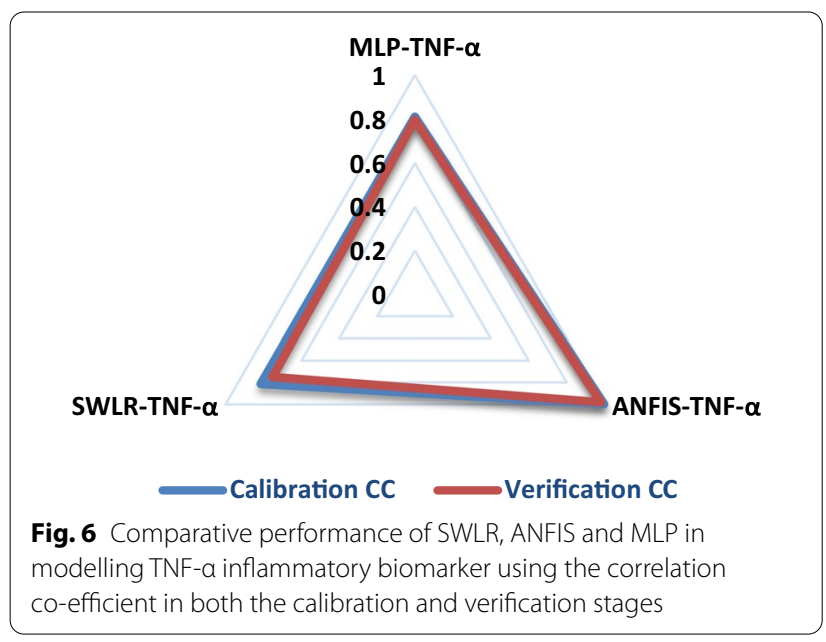

and many more. The most important benefit of the $\mathrm{k}$ fold cross-validation procedue is because the validation and training sets are independent (Selin and Abba 2020). Therefore, in this work, we have categorized the data into $75 \%$ for the calibration (training) and $25 \%$ for the testing (verification) stage, based on the k-fold cross-validation. Therefore, its is essential to know that other models of validation could be applied to the data set (Abba et al. 2020a, b, c). Besides, the data set were obtained over two months, where the data set comprised of 64 instances for each of the variables.

\section{The proposed methodology}

It is significant to understand the science and knowledge of the data used during any data-driven technique (Barmpalexis et al. 2018). The data employed in this study was generated from our experimental studies. This research employed the use of three data-driven approaches MLP, ANFIS and SWLR models, for modelling four different inflammatory biomarkers; IL-6, IL-1B, TNF- $\alpha$ and PGE2 using number of abdominal writhes, number of paw licking and paw oedema diameter $(\mathrm{mm})$ as independent variables.

One of the significant objectives of using different modelling methods is due to the limitation in understanding the model that has higher prediction performance skills than the others in practice (Abba et al. 2020a, b, c). Therefore, selecting a particular model for a specific data set is challenging.

\section{Results}

The main enthusiasm of this study is to comparatively develop various data-driven techniques for the modelling of four inflammatory biomarkers; IL-1B, IL-6, TNF- $\alpha$ and PGE2. In this section, the obtained results are shown both quantitatively and in a visualized form. Table 1 demonstrates the correlation analysis of the variables involved in the study (Ghali et al. 2020), namely, number of abdominal writhes, number mean reaction time of paw licking and paw oedema diameter. Acetic acid-induced abdominal writhes result from the stimulation of the release of arachidonic acid to form PG that plays a critical role in pain mechanism. The model depicts a peripheral analgesic mechanism (Ofuegbe et al. 2014). The measurement of the mean reaction time in mice in the hot plate test of algesia is used to investigate the analgesic action of centrally acting agents via an increase in pain threshold in mice. It also predicts the potential involvement of narcotic analgesic agents (Ibrahim et al. 2012). Injection of carrageenan into the paw of the rats causes the release of inflammatory mediators including bradykinin, histamine, serotonin and prostaglandins that subsequently stimulate the production and release of TNF- $\alpha$. The cascade of the event causes the release of other pro-inflammatory

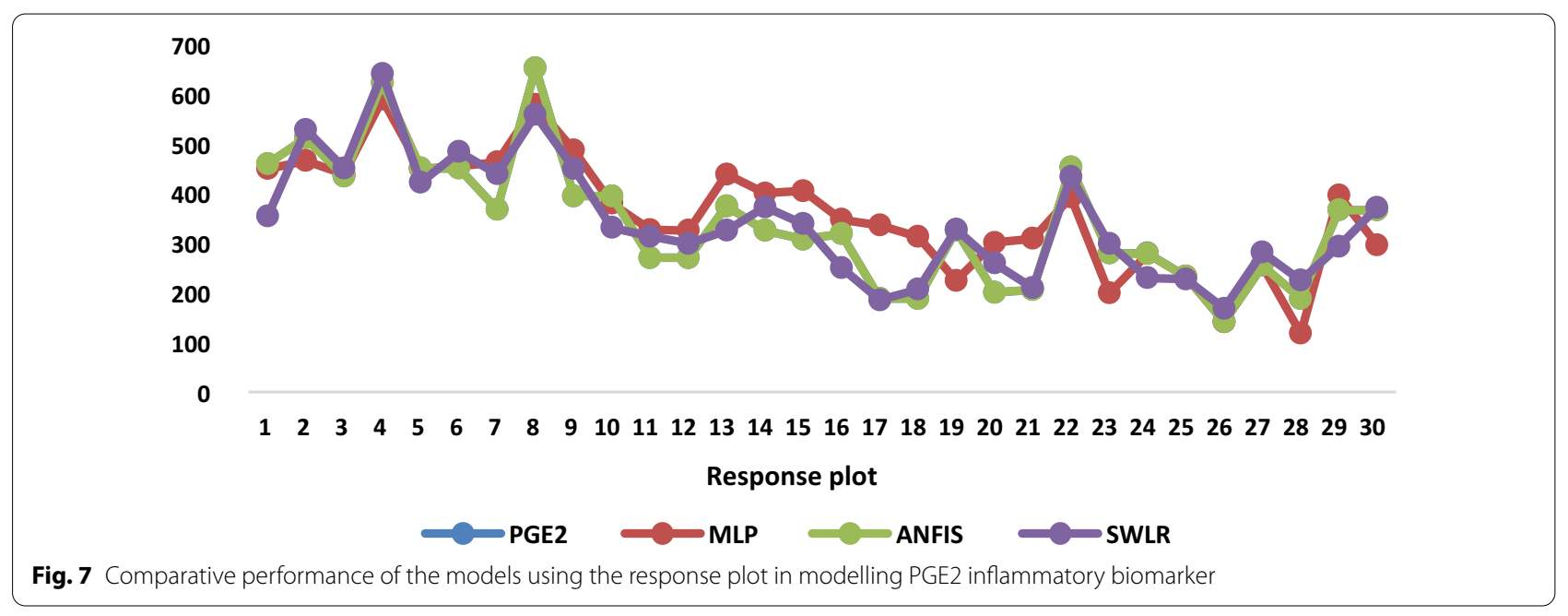



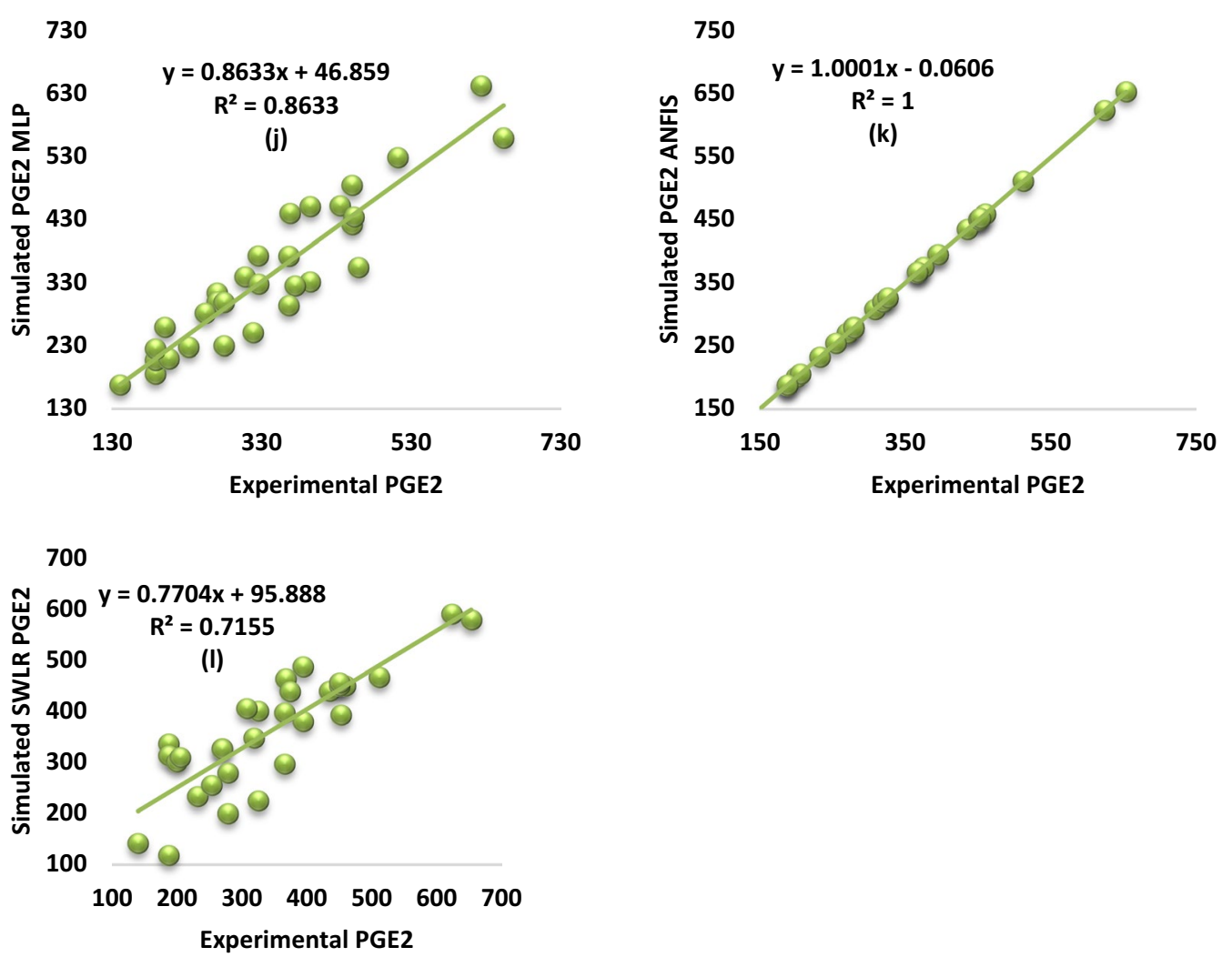

Fig. 8 Scatter plots for $\mathbf{j} M L P, \mathbf{k}$ ANFIS and I SWLR for PGE2

Table 5 Performance of PGE2inflammatory biomarker

\begin{tabular}{|c|c|c|c|c|c|c|c|c|}
\hline \multirow[t]{2}{*}{ Models } & \multicolumn{4}{|c|}{ Calibration } & \multicolumn{4}{|c|}{ Verification } \\
\hline & DC & $\mathrm{CC}$ & RMSE & MSE & DC & $\mathrm{CC}$ & RMSE & MSE \\
\hline MLP-PGE2 & 0.65 & 0.80 & 75.96 & 5770.56 & 0.72 & 0.85 & 31.40 & 986.05 \\
\hline ANFIS-PGE2 & 1.00 & 1.00 & 0.00 & 0.00 & 1.00 & 1.00 & 0.22 & 0.05 \\
\hline SWLR-PGE2 & 0.85 & 0.92 & 49.63 & 2463.26 & 0.85 & 0.92 & 23.26 & 540.84 \\
\hline
\end{tabular}

The best performing model are written in bold

$\mathrm{DC}=$ Determination co-efficient, $\mathrm{CC}=$ Correlation co-efficient, $\mathrm{RMSE}=$ Root mean square error, $\mathrm{MSE}=$ Mean square error, $n=6$

cytokines such as IL-1 $\beta$. The cytokines enhance the production of PG from arachidonic acid by the action COXs (Kumar and Jitendra 2009).

To improve the methodologies of the models, assurance of the correlation co-efficient conducted are presented in Table 1, Where the guiding symbols (+ or - ) shows the connection among the variables (Usman et al. 2020a, b). The correlation analysis helps us in determining the highest and lowest parameters related to one another (Khalid and Usman 2021). More also, it helps in understanding the science and the mechanism of the data prior to dwelling into the modelling method by showing the input parameter with the highest correlation with the output variable (Usman et al. 2020a, b).

\section{Performance of the data-driven techniques}

As described in the methodology section, the simulation was conducted using MATLAB 9.3 (R2020a).

\section{Discussion}

For the MLP and ANFIS models, the best architecture was optimized and selected using the trial and error technique. The results of the simulation were checked and evaluated using DC and CC to check for the fitness 
between the experimental and predicted values, while RMSE and MSE were employed in order to determine the error depicted by the models in both the training and testing phases.

A comparative analysis of three different data-driven techniques (MLP, ANFIS and SWLR models) were depicted in Table 2 for the simulation of IL- $1 \beta$ inflammatory biomarker. The obtained results showed that ANFIS-IL-1 $\beta$ and MLP-IL-1 $\beta$ AI-based models demonstrated higher prediction skills as compared to the SWLR-IL-1 $\beta$ (linear model). It is not surprising that the ANFIS-IL-1 $\beta$ showed the highest prediction, which is considered as a hybrid emerging system for modelling highly complex data. The models' performance efficiency can be demonstrated based on the hierarchical order ANFIS-IL- $1 \beta>$ MLP-IL- $1 \beta>$ SWLR-IL- $1 \beta$. This can be shown visually using a scatter plot, which indicated the fitness between the experimental and predicted values (see Fig. 1).

It is evident that the AI-based models are superior to the classical linear model SWLR-IL-1 $\beta$ by depicting lower error values as shown in Fig. 2. This is in line with the performance of the models shown in Table 2 in both the training and testing phases.

As shown in Table 3, it can be observe that only the emerging non-linear AI-based model ANFIS was able to capture the performance of the IL- 6 biomarker with a fitness performance of more than $80 \%$ using its determination co-efficient in both the calibration and verification phases. Therefore, ANFIS has the ability to boost the performance skills of both MLP and SWLR models by $20.28 \%$ and $26.17 \%$ in the calibration and $35.5 \%$ and $38.66 \%$ in the verification stage respectively. The performance skills of the models can be graphically illustrated using the scatter plot (see Fig. 3).

The performance accuracy of these models can equally be comparatively determined using their respective MSE, and this can be graphically demonstrated using the bar chart plot (see Fig. 4).

Based on the chart, it can be seen that the increasing order of the models' performance can be as follows SWLR-IL-6 < MLP-IL-6 < ANFIS-IL-6.

The performance indices for the data-driven approaches used in modelling TNF- $\alpha$ inflammatory biomarker are shown in Table 4 . The comparative performance of the models showed that only ANFIS has the ability to model TNF- $\alpha$ inflammatory biomarker with a minimum of $80 \%$ fitness in both the training and testing stages, respectively. Therefore, this proves the ability of AI-based models in capturing highly chaotic and complex system. Furthermore, the performance of these models can be graphically demonstrated using the scatter plot (see Fig. 5).
Moreover, the performance of the models can be equally shown graphically using a radar plot. This plot generally demonstrates the comparative performance fitness of data-driven techniques using either their DC or CC. Whereby, in this current research, the performance of the models were checked using the CC evaluation metric in both the calibration and the verification phases (see Fig. 6).

The performance accuracy of three data-driven techniques for modelling PGE2 inflammatory biomarker. Based on the obtained results, it can be observed that the two non-linear AI-based models outperformed the classical linear model SWLR-PGE2. Furthermore, both MLPPGE2 and ANFIS-PGE2 were able to simulate the PGE2 inflammatory biomarker with a minimum fitness of $80 \%$, whereby the SWLR-PGE2 failed in both the calibration and verification stages. The overall performance of the models showed that ANFIS-PGE2 outperformed both MLP-PGE2 and SWLR-PGE2, which increased their performance skills by $15 \%$ and $28 \%$ in the verification stage, respectively. The response plot can be used to graphically illustrate the comparative performance of the models (see Fig. 7).

Based on Fig. 7, it can be observed that ANFIS-PGE2 showed the highest fitness in capturing the oscillation of the experimental values. Moreover, the performance of the models can equally be depicted using the scatter plot (see Fig. 8).

\section{Conclusion}

In this research, three different data-driven approaches, MLP, ANFIS and SWLR models, were employed for the simulation of four different inflammatory biomarkers; IL-1 $\beta$ B,IL-6,TNF- $\alpha$ and PGE2. The performance indices used in the work, namely DC, CC, RMSE and MSE, proved the ability of the AI-based models (ANFIS and ANN) over the classical linear model (SWLR) in modelling the four inflammatory biomarkers in both the calibration and verification stages (see Table 5).

Overall, the comparative performance of the models demonstrates that ANFIS exhibited higher performance skills in modelling the performance of the inflammatory biomarkers in both the training and testing stages. It is recommended that other models and optimization algorithms such as support vector machine (SVM), extreme learning machine (ELM), Harris Hawks' optimization (HHO) technique, genetic algorithms (GA) and particle swarm optimization (PSO) to be employed in order to boost the prediction ability of the inflammatory biomarkers. 


\section{Abbreviations}

Al: Artificial intelligence; ANFIS: Adaptive neuro-fuzzy inference system; ANN: Artificial neural network; CC: Correlation co-efficient; COX: Cyclooxygenase; DC: Determination coefficient; EDTA: Ethylenediaminetetraacetic acid; EEHF: Ethanolic leaves extract of Hymenodictyon floribundun"; IL: Interleukins; LD 50 : Median lethal dose; MSE: Mean square error; N: Number of abdominal writes; NSAIDs: Non-steroidal anti-inflammatory drugs; OECD: Organization of Economic Co-operation and Development; RMSE: Root mean squared error; SWLR: Stepwise linear regression; TNF-a: Tumour necrosis factor a.

\section{Acknowledgements}

The authors are thankful to the staff of department of Pharmacology and Pharmacology, Ahmadu Bello University, Zaria, Nigeria for supporting this research.

\section{Authors' contributions}

AU: Conceptualization, data analysis, writing the manuscript and review. MHA: Conceptualization, writing original draft and review. RND: Conceptualization, data curation and conducting the pharmacological investigation. SIA: Supervised and critically revised the manuscript. All the authors read and approved the manuscript.

\section{Funding}

Not applicable.

\section{Availability of data and materials}

Thedata are provided in the main manuscript.

\section{Declarations}

\section{Ethics approval and consent to participate}

The experimental protocols were approved by the Ahmadu Bello University, Ethical Committee on Animal Use and Care Zaria (ethical approval number: ABUCAUC/2020/011).

\section{Consent for publication}

Not applicable.

\section{Competing interests}

The authors declared that there is no any personal or financial competing interest to declare.

\section{Author details}

${ }^{1}$ Department of Analytical Chemistry, Faculty of Pharmacy, Near East University, Nicosia 99138, Turkish Republic of Northern Cyprus. ${ }^{2}$ Department of Pharmacology and Therapeutics, Ahmadu Bello University, Zaria, Nigeria. ${ }^{3}$ Department of Civil Engineering, Baze University, Abuja, Nigeria.

Received: 27 March 2021 Accepted: 6 July 2021

Published online: 19 July 2021

\section{References}

Abba SI, Hadi SJ, Sammen SS, Salih SQ, Abdulkadir RA, Pham QB, Yaseen ZM (2020a) Evolutionary computational intelligence algorithm coupled with self-tuning predictive model for water quality index determination. J Hydrol 587(March):124974. https://doi.org/10.1016/j.jhydrol.2020.124974

Abba SI, Usman AG, Is S (2020b) Chemometrics and Intelligent Laboratory Systems Simulation for response surface in the HPLC optimization method development using arti fi cial intelligence models: a data-driven approach. Chemometr Intell Lab Syst. https://doi.org/10.1016/j.chemo lab.2020.104007

Abba SI, Usman AG, Işik S (2020c) Simulation for response surface in the HPLC optimization method development using artificial intelligence models: A data-driven approach. Chemom Intell Lab Syst. https://doi.org/10.1016/j. chemolab.2020.104007

Abdullahi HU, Usman AG, Abba SI (2020) Modelling the absorbance of a bioactive compound in HPLC method using artificial neural network and multilinear regression methods. Dutse J Pure AppI Sci DUJOPAS 6(2):362-371
Abdulmalik IA, Sule MI, Musa AM, Yaro AH, Abdullahi MI, Abdulkadir MF, Yusuf $H(2011)$ Evaluation of analgesic and anti-inflammatory effects of ethanol extract of Ficus iteophylla leaves in rodents. Afr J Tradit Complement Altern Med 8(4):462-466. https://doi.org/10.4314/ajtcam.v8i4.19

Abubakar A, Nazifi AB, Odoma S, Shehu S, Danjuma NM (2020) Antinociceptive activity of methanol extract of Chlorophytum alismifolium tubers in murine model of pain: Possible involvement of a2-adrenergic receptor and KATP channels. J Tradit Complement Med 10(1):1-6. https://doi.org/ 10.1016/j.jtcme.2019.03.005

Adedayo LD, Ojo AO, Awobajo FO, Adeboye BA, Adebisi JA, Bankole TJ, Ayilara GO, Bamidele O, Aitokhuehi NG, Onasanwo SA (2019) Methanol extract of Cola nitida ameliorates inflammation and nociception in experimental animals. Neurobiol Pain 5(August 2018):100027. https://doi.org/10.1016/j. ynpai.2019.100027

Akindele AJ, Ibe IF, Adeyemi OO (2012) Analgesic and antipyretic activities of Drymaria cordata (Linn.) Willd (Caryophyllaceae) extract. Afr J Tradit Complem Altern Med 9(1):25-35. https://doi.org/10.4314/ajtcam.v9i1.4

Azab A, Nassar A, Azab AN (2016) Anti-inflammatory activity of natural products. Molecules 21(10):1-19. https://doi.org/10.3390/molecules21101321

Ballou LR, Botting RM, Goorha S, Zhang J, Vane JR (2000) Nociception in cyclooxygenase isozyme-deficient mice. Proc Natl Acad Sci USA 97(18):10272-10276. https://doi.org/10.1073/pnas.180319297

Barmpalexis P, Karagianni A, Karasavvaides G, Kachrimanis K (2018) Comparison of multi-linear regression, particle swarm optimization artificial neural networks and genetic programming in the development of mini-tablets. Int J Pharm 551(1-2):166-176. https://doi.org/10.1016/j.ijpharm.2018.09. 026

Borges CMP, Diakanawma C, De Mendonça DIMD (2010) Iridoids from Hymenodictyon foribundum. J Braz Chem Soc 21(6):1121-1125. https://doi. org/10.1590/S0103-50532010000600023

Chagas-Paula DA, Oliveira TB, Zhang T, Edrada-Ebel R, Da Costa FB (2015) Prediction of anti-inflammatory plants and discovery of their biomarkers by machine learning algorithms and metabolomic studies. Planta Med 81(6):450-458. https://doi.org/10.1055/s-0034-1396206

Choubin B, Khalighi-Sigaroodi S, Malekian A, Kişi Ö (2016) Multiple linear regression, multi-layer perceptron network and adaptive neuro-fuzzy inference system for forecasting precipitation based on large-scale climate signals. Hydrol Sci J 61(6):1001-1009. https://doi.org/10.1080/ 02626667.2014.966721

Committee AT (2000) Artificial neural networks in hydrology. I: preliminary concepts. J Hydrol Eng 5(2):115-123

Elkiran G, Nourani V, Abba SI (2019) Multi-step ahead modelling of river water quality parameters using ensemble artificial intelligence-based approach. J Hydrol 577(April):123962. https://doi.org/10.1016/j.jhydrol.2019.123962

England S, Bevan S, Docherty RJ (1996) PGE2 modulates the tetrodotoxinresistant sodium current in neonatal rat dorsal root ganglion neurones via the cyclic AMP-protein kinase A cascade. J Physiol 495(2):429-440. https://doi.org/10.1113/jphysiol.1996.sp021604

Ezeja M, Omeh Y, Ezeigbo I, Ekechukwu A (2011) Evaluation of the analgesic activity of the methanolic stem bark extract of dialium guineense (wild). Ann Med Health Sci Res 1(1):55-62

Gaya MS, Abba SI, Abdu AM, Tukur Al, Saleh MA, Esmaili P, Wahab NA (2020) Estimation of water quality index using artificial intelligence approaches and multi-linear regression. IAES Int J Artif Intell 9(1):126-134. https://doi. org/10.11591/ijai.v9.i1.pp126-134

Ghali UM, Usman AG, Chellube ZM, Degm MAA, Hoti K, Umar H, Abba SI (2020) Advanced chromatographic technique for performance simulation of anti-Alzheimer agent: an ensemble machine learning approach. SN Appl Sci. https://doi.org/10.1007/s42452-020-03690-2

Ibrahim B, Sowemimo A, Van Rooyen A, Van De Venter M (2012) Antiinflammatory, analgesic and antioxidant activities of Cyathula prostrata (Linn.) Blume (Amaranthaceae). J Ethnopharmacol 141(1):282-289. https://doi. org/10.1016/j.jep.2012.02.032

Kapugi M, Cunningham K (2019) Corticosteroids. Orthop Nurs 38(5):336-339. https://doi.org/10.1097/NOR.0000000000000595

Kearney PM, Baigent C, Godwin J, Halls H, Emberson JR, Patrono C (2006) Do selective cyclo-oxygenase- 2 inhibitors and traditional non-steroidal antiinflammatory drugs increase the risk of atherothrombosis? Meta-analysis of randomised trials. BMJ 332(7553):1302-1305. https://doi.org/10.1136/ bmj.332.7553.1302 
Khademi F, Jamal SM, Deshpande N, Londhe S (2016) Predicting strength of recycled aggregate concrete using Artificial Neural Network, Adaptive Neuro-Fuzzy Inference System and Multiple Linear Regression. Int J Sustain Built Environ 5(2):355-369. https://doi.org/10.1016/j.ijsbe.2016.09.003

Khalid GM, Usman AG (2021) Application of data-intelligence algorithms for modeling the compaction performance of new pharmaceutical excipients

Kim JH, Lee HS (2017) Improvement of early strength of cement mortar containing granulated blast furnace slag using industrial byproducts. Materials. https://doi.org/10.3390/ma10091050

Kim S, Singh VP (2014) Modeling daily soil temperature using data-driven models and spatial distribution. Theoret Appl Climatol 118(3):465-479. https://doi.org/10.1007/s00704-013-1065-z

Kumar Manna Ashis JJ (2009) Anti-inflammatory and analgesic activity of bark extract of pterospermum acerifolium. Int J Curr Pharm Res 1(1):32-37

Lee JK, Han WS, Lee JS, Yoon CN (2017) A novel computational method for biomedical binary data analysis: development of a thyroid disease index using a brute-force search with MLR analysis. Bull Korean Chem Soc 38(12):1392-1397. https://doi.org/10.1002/bkcs.11308

Mohammadhassani M, Nezamabadi-Pour H, Jumaat MZ, Jameel M, Arumugam AMS (2013) Application of artificial neural networks (ANNs) and linear regressions (LR) to predict the deflection of concrete deep beams. Comput Concr 11(3):237-252. https://doi.org/10.12989/cac.2013.11.3.237

Montgomery SL, Bowers WJ (2012) Tumor necrosis factor-alpha and the roles it plays in homeostatic and degenerative processes within the central nervous system. J Neuroimmune Pharmacol 7(1):42-59. https://doi.org/ 10.1007/s11481-011-9287-2

Neamul Kabir Zihad SM, Bhowmick N, Uddin SJ, Sifat N, Shamim Rahman M, Rouf R, Islam MT, Dev S, Hazni H, Aziz S, Ali ES, Das AK, Shilpi JA, Nahar L, Sarker SD (2018) Analgesic activity, chemical profiling and computational study on chrysopogon aciculatus. Front Pharmacol 9(8):1-8. https://doi. org/10.3389/fphar.2018.01164

Organisation for Economic Cooperation and Development (OECD) (2001) Guidelines for the testing of chemicals: health effect test no. 423. Acute Oral Toxicity-Acute Toxic Class Method, Paris, France

Ofuegbe SO, Adedapo AA, Adeyemi AA (2014) Anti-inflammatory and analgesic activities of the methanol leaf extract of Phyllanthus amarus in some laboratory animals. J Basic Clin Physiol Pharmacol 25(2):175-180. https:// doi.org/10.1515/jbcpp-2013-0084

Okolo CO, Johnson PB, Abdurahman EM, Abdu-Aguye I, Hussaini IM (1995) Analgesic effect of Irvingia gabonensis stem bark extract. J Ethnopharmacol 45(2):125-129. https://doi.org/10.1016/0378-8741(94)01199-A

Okpo SO, Fatokun F, Adeyemi OO (2001) Analgesic and anti-inflammatory activity of Crinum glaucum aqueous extract. J Ethnopharmacol 78(2-3):207-211. https://doi.org/10.1016/S0378-8741(01)00318-X

Pandya PN, Kumar SP, Bhadresha K, Patel CN, Patel SK, Rawal RM, Mankad AU (2020) Identification of promising compounds from curry tree with cyclooxygenase inhibitory potential using a combination of machine learning, molecular docking, dynamics simulations and binding free energy calculations. Mol Simul 46(11):812-822. https://doi.org/10.1080/ 08927022.2020 .1764552
Pham QB, Abba SI, Usman AG, Linh NTT, Gupta V, Malik A, Costache R, Vo ND, Tri DQ (2019) Potential of hybrid data-intelligence algorithms for multistation modelling of rainfall. Water Resour Manag. https://doi.org/10. 1007/s11269-019-02408-3

Rafieian-kopaei M, Shakiba A, Sedighi M, Bahmani M (2017) The analgesic and anti-inflammatory activity of linum usitatissimum in Balb/c mice. J Evid Based Comple Altern Med 22(4):892-896. https://doi.org/10.1177/21565 87217717416

Rider P, Carmi Y, Voronov E, Apte RN (2013) Interleukin-1a. Semin Immunol 25(6):430-438. https://doi.org/10.1016/j.smim.2013.10.005

Schneider V, Lévesque LE, Zhang B, Hutchinson T, Brophy JM (2006) Association of selective and conventional nonsteroidal antiinflammatory drugs with acute renal failure: a population-based, nested case-control analysis. Am J Epidemiol 164(9):881-889. https://doi.org/10.1093/aje/kwj331

Selin AGU, Abba ISI (2020) A novel multi- model data-driven ensemble technique for the prediction of retention factor in HPLC method development. Chromatographia. https://doi.org/10.1007/s10337-020-03912-0

Shiri R, Koskimäki J, Häkkinen J, Tammela TLJ, Auvinen A, Hakama M (2006) Effect of nonsteroidal anti-inflammatory drug use on the incidence of erectile dysfunction. J Urol 175(5):1812-1816. https://doi.org/10.1016/ S0022-5347(05)01000-1

Usman AG, Işik S, Abba SI (2020a) A novel multi-model data-driven ensemble technique for the prediction of retention factor in HPLC method development. Chromatographia. https://doi.org/10.1007/s10337-020-03912-0

Usman AG, IŞik S, Abba SI, MeriÇII F (2020) Artificial intelligence-based models for the qualitative and quantitative prediction of a phytochemical compound using HPLC method. Turkish J Chem 44(5):1339-1351. https://doi. org/10.3906/kim-2003-6

Winter CA, Risley EA, Nuss GW (1962) Carrageenin-induced edema in hind paw of the rats as an assay for antiinflammatory drugs. Exp Biol Med 3(111):544-547

Xu X, Yang K, Zhang F, Liu W, Wang Y, Yu C, Wang J, Zhang K, Zhang C, Nenadic G, Tao D, Zhou X, Shang H, Chen J (2020) Identification of herbal categories active in pain disorder subtypes by machine learning help reveal novel molecular mechanisms of algesia. Pharmacol Res 156(March):104797. https://doi.org/10.1016/j.phrs.2020.104797

Yemitan OK, Adeyemi OO (2017) Mechanistic assessment of the analgesic, anti-inflammatory and antipyretic actions of Dalbergia saxatilis in animal models. Pharm Biol 55(1):898-905. https://doi.org/10.1080/13880209. 2017.1283706

Zelová H, Hošek J (2013) TNF-a signalling and inflammation: Interactions between old acquaintances. Inflamm Res 62(7):641-651. https://doi.org/ 10.1007/s00011-013-0633-0

\section{Publisher's Note}

Springer Nature remains neutral with regard to jurisdictional claims in published maps and institutional affiliations.

\section{Submit your manuscript to a SpringerOpen ${ }^{\odot}$ journal and benefit from:}

- Convenient online submission

- Rigorous peer review

- Open access: articles freely available online

- High visibility within the field

- Retaining the copyright to your article

Submit your next manuscript at $\boldsymbol{\nabla}$ springeropen.com 